\title{
Research Article \\ Photovoltaic Generation Integration with Radial Feeders Using GA and GIS
}

\author{
Elias Mandefro Getie $\mathbb{D}^{D}$, Belachew Bantyirga Gessesse, and Tewodros Gera Workneh
}

Bahir Dar Institute of Technology, Bahir Dar University, Bahir Dar, Ethiopia

Correspondence should be addressed to Elias Mandefro Getie; eliasmandefro01@gmail.com

Received 22 July 2020; Revised 15 September 2020; Accepted 24 September 2020; Published 17 October 2020

Academic Editor: Dhruba B. Khadka

Copyright (C) 2020 Elias Mandefro Getie et al. This is an open access article distributed under the Creative Commons Attribution License, which permits unrestricted use, distribution, and reproduction in any medium, provided the original work is properly cited.

\begin{abstract}
The electric power generated from different electricity sources are not used efficiently by end users in the world. This is due to the loss of power supplied in the case of electricity transmission and distribution to residential, commercial, and industrial loads. Even if the loss of power in the power system cannot be avoided $100 \%$, it should be reduced to the minimum optimal value. The loss of power in the radial feeders can be minimized using an optimally allocated photovoltaic (PV) generation system by considering the information of geography, solar irradiance of the site, and space availability, which should not have shadow from large buildings and trees. The PV generation system eliminates the problem of power demand by enhancing the capacity of the power network as well as by reducing the depletion and consumption of fossil fuel resources. To reduce power loss and improve system loading capacity for demand response, the integration and finding the optimal place of photovoltaic generation take high concern from power system operators and technicians. The optimal allocation of PV has been done using the Genetic Algorithm (GA) for optimization of a multiobjective function with different constraints. The main objective of this paper is to minimize the power loss of the radial distribution networks by maintaining the phase voltage of the load in balance and improving the drop in voltage along the phase. So, GA is used to determine the best location and capacity of PV generation that can reduce the loss of power in the system. The IEEE-33 bus system is used to test the proposed method. Generally, using the GA and GIS methods results in a high accuracy for optimal placement of PV generation in the IEEE-33 bus radial feeder and enables to reduce the loss of power during transmission and distribution by maintaining the power quality for consumers.
\end{abstract}

\section{Introduction}

Distribution systems and loads are a crucial part of a power system exposed to different phenomena which may disturb system performance. The quality of power required by the end users is not met by power generations. There is a difference in the required and supplied electrical power. Using capacitors is one of the conventional methods to improve the quality of power at the load. Power-conditioning devices are also used to compensate for the reactive power and to maintain the voltage in the desired limit. Integration of a photovoltaic generation system to the load can also be another alternative to mitigate the power quality issue [1]. The poor power quality in the distribution system indicates the existence of power loss during distribution to consumers. The expansion of urbanization and power demand need a solution to continue to end users. Global warming and change in weather condition force the use of renewabletype generations which are available in the site.

Photovoltaic generation is currently the best option to mitigate the problem of power demand and to reduce the depletion of nonrenewable energy resources used for electrical energy. The civilization of the people and growth of technology need alternative energy resources which are environmentally friendly. PV generation is environmentally friendly and naturally available with low maintenance cost [1]. Currently, the installation of PV-based distributed generation gets more attention. Major impacts of PV integration on the distribution systems are reverse power flow, rise, and fluctuation of voltage [2]. The high penetration of PV generation can reverse active power flow at transformers and feeders. This phenomenon may cause the disorder of line 
voltage regulators and over current protection coordination. The coordination of protection devices may be affected which might disable the operation within the desired range. The penetration level and its capacity to deliver after installation of PV-based distributed generation can determine the quality of power supplied by distribution systems [3].

The planning of PV generation by using GIS technology brings better solution for radial distribution network performance enhancement. The geographic information system (GIS) is capable of determining the optimal place for solar power deployment in buildings, rivers, dams, and free lands suitable for PV integration. The energy delivered from renewable energy sources depends on geographical conditions, climate, and morphological features of the site (typology of roof exposure, height of buildings, presence of obstacles, and trees) [4]. The optimization techniques need helping tools like GIS to check the reality of the earth to implement the solar power in a radial distribution network. The methods used for finding an optimal place and size of PV generation for grid connection require a strategic place of installation, and this can be done using GIS [5].

1.1. Photovoltaic Generation. Photovoltaic (PV) generation is a process of producing electric energy from sunlight. The free availability of sunlight energy in different sites of the globe can help to reduce the global warming effect. The effect of natural uncertainty of PV generation can be compromised using power electronic converters. The integration of PV generation to a distribution system can have positive and negative impacts on power loss reduction [6]. To gain the advantage of using PV generation, finding the most suitable place and capacity of PV require smart techniques [7]. The structure of $\mathrm{PV}$ generation integration for performance optimization is shown in Figure 1.

\section{Literature Review}

Saggu and Singh [9] did a comparative analysis on power quality improvement and mitigation techniques in residential and industrial consumers. Using a distribution static compensator and a dynamic voltage restorer, they were able to maintain the voltage profile in the given limit when properly controlled. This research addresses only power quality improvement techniques without comparing the effect of PV generation integration in radial feeders.

Anjana et al. [10] suggested on the problem of integrating PV source of microgrids. A fuzzy controller is used to control the DC output voltage from PV. The shunt active power filters improve the power quality of the network like harmonics reduction. The dynamic and steady-state performance of the system was studied in the presence of PV generation. The power factor improvement is not done in this research.

Pannase and Nanavala [11] did a review on PV technology application. From this research, PV technology can enhance the alternative of power consumption and was found to be a solution for rapid power demand growth. The integration PV technology is not supported by optimization techniques. In this research, we looked into the optimal

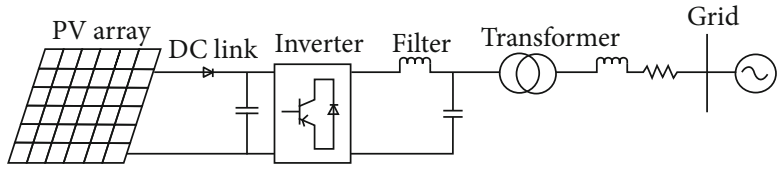

FIgURE 1: Schematic diagram of PV integration to a distribution system [8].

allocation of $\mathrm{PV}$ generation and its contribution in power quality improvement.

Teli and Jadhav [12] proposed on the protection of a capacitor to improve the quality of power in industries. The inrush currents drawn to the capacitor bank may cause failure of equipment. MATLAB Simulink is used to simulate and analyze the effects of capacitor protection on quality of power supplied to industries. The placement of protection devices is not done based on finding the best place that can assure standard power quality. The effect of PV generation on power quality and capacitor placement with different artificial intelligence techniques is not studied.

Praiselin and Edward [13] studied on power quality improvement with integration of PV generation. The battery storage is used to compensate for the voltage between the microgrid and PV generation. The current and voltage harmonics are reduced when load is connected to the utility after PV generation. The controller enhances the voltage profile of the system. In this research, finding the best place and size of PV generation is not studied.

Khattak et al. [14] proposed on radial distribution network optimization using GIS and GPS technologies. The GIS technology enables to establish reliable information management and planning of the distribution system. The global positioning system helps to know the places needed for electric pole installment during planning for the distribution system. In this research, the optimal place of PV generation is not studied by using other optimization techniques.

\section{Formulation of Objective Problem}

An efficient and standard power flow method is required for real-time applications such as switching, planning, load shading, and optimization of network. Load flow analysis of radial feeders is done using the Backward/Forward Sweep (BFS) algorithm [15].

3.1. Load Flow Analysis. Load flow analysis is the backbone for a power system. Different load flow techniques are used to know the status of power flow in distribution systems. The radial nature of a distribution network is more suitable to compute load flow using the Backward/Forward load flow method rather than the Gauss-Sediel, Newton-Raphson, and Fast-decouple methods [16].

The total power loss of a radial distribution feeder is obtained as

$$
P_{\text {loss }}=\sum_{i=1}^{N} R_{\mathrm{i}} * I_{i}^{2}
$$


where $N$ is total branches, $i$ the branch number, $I_{i}$ the $i^{\text {th }}$ branch current, $R_{i}$ the $i^{\text {th }}$ branch resistance, and $P_{\text {loss }}$ the active power loss in the distribution network.

The reduction index of power loss (RIPL) can be found as

$$
f_{1}=\mathrm{RIPL}=\frac{P_{\text {loss }(\mathrm{PV})}}{P_{\text {loss(base })}},
$$

where $P_{\text {loss(PV) }}$ is power loss with $\mathrm{PV}$ and $P_{\text {loss(base) }}$ is power loss without PV.

The objective function is to minimize the real power loss and maximize the voltage profile of radial feeders. The multiobjective function of this research is considered to minimize the real power loss and Voltage Deviation Index(VDI):

$$
\operatorname{Minimize}(f)=\min \left(w_{1} * f_{1}+w_{2} * f_{2}\right) \text {, }
$$

where $i$ is the bus number, $V_{i}$ the node voltage at bus $i$, and $N$ the number of nodes,

$$
\begin{aligned}
& f_{2}=\mathrm{VDI}=\sum_{i=1}^{N}\left(1-v_{i}\right)^{2} \\
& w_{1}+w_{2}=1
\end{aligned}
$$

subject to

$$
\left\{\begin{array}{l}
\sum P_{\mathrm{PV}}+P_{\text {grid }}=\sum P_{\text {loss }}+P_{\mathrm{d}}, \\
0.95 \leq V_{i} \leq 1.05, \\
w_{1}+w_{2}=1, \\
P_{\mathrm{PV}}^{\min } \leq P_{\mathrm{PV}} \leq P_{\mathrm{PV}}^{\max } .
\end{array}\right.
$$

3.2. Bus Sensitivity Determination. Bus sensitivity determination needs to determine the weak bus for the optimal allocation of PV generation. From 33 nodes of the IEEE-33 bus test system using VSI, the most sensitive bus is determined, and its effect for loss reduction is checked. The voltage sensitivity index (VSI) is as follows:

$$
\mathrm{VSI}=V_{i} / 0.95 .
$$

\section{Genetic Algorithm}

Genetic Algorithm (GA) is one of the searching and optimization techniques that depend on the natural selection and genetics [17]. GA is suggested by Holland in 1975 and is inspired by law of generation and natural selection and most evolutionary-based popular algorithm [17]. The importance of using GA for PV allocation has proved to be an efficient technique and a best option for PV location. Some literatures indicate that multiobjective optimization has more significance when PV is integrated with voltage profile and power loss minimization [18]. The steps included in GA optimization are explained what follows:

(a) Generate initial population: randomly generated by picking the genes of chromosomes
TABLE 1: GA algorithm input parameters.

\begin{tabular}{lcc}
\hline No. & Elements & Values \\
\hline 1 & Population size & 40 \\
2 & Maximum iteration & 50 \\
3 & Mutation probability & 0.03 \\
4 & Crossover probability & 0.8 \\
5 & $w_{1}$ & 0.6 \\
6 & $w_{2}$ & 0.4 \\
\hline
\end{tabular}

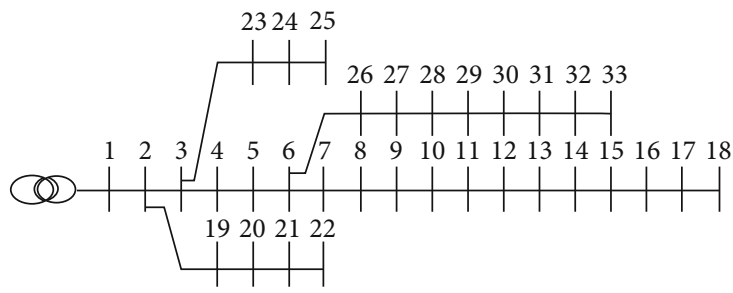

Figure 2: Map of the IEEE-33 bus radial distribution system.

(b) Calculate the objective function fitness value

(c) Check algorithm termination: it is best to stop the optimization by checking the value of the objective function, maximum number of iterations, and stall generation

(d) Selection: the best $n$ individuals are directly transferred to the next generation

(e) Crossover: used to get offspring individuals that bring the best possible alternative genes

(f) Mutation: helps to find the extremum

(g) New generation: used to form the next generation

\section{Candidate Bus Identification}

The proposed methods based on GA optimization for PV generation integration and size determination in a radial feeder is expressed as follows:

Step 1. Input line and load data of radial feeders including base MVA and KV.

Step 2. . Use the BFS load flow technique [19] and calculate power loss of radial feeders using (1).

Step 3. Initialize the GA parameters as given in Table 1 .

Step 4. Limit the maximum capacity of PV generation and its location based on VSI value, i.e., VSI < 1.0.

Step 5. Check the constraints and the objective function within the desired limit.

Step 6. Calculate the fitness function and arrange from minimum to maximum values. 
TABLE 2: Line and load data of an IEEE-33 bus system.

\begin{tabular}{|c|c|c|c|c|c|c|}
\hline \multirow{2}{*}{ Branch number } & \multirow{2}{*}{ Sending bus } & \multirow{2}{*}{ Receiving bus } & \multirow{2}{*}{ Resistance (ohm/km) } & \multirow{2}{*}{ Reactance $(\mathrm{ohm} / \mathrm{km})$} & \multicolumn{2}{|c|}{$\begin{array}{l}\text { Nominal load at } \\
\text { receiving bus }\end{array}$} \\
\hline & & & & & $P(\mathrm{~kW})$ & $Q$ (kVAr) \\
\hline 1 & 1 & 2 & 0.0922 & 0.047 & 100 & 60 \\
\hline 2 & 2 & 3 & 0.493 & 0.2511 & 90 & 40 \\
\hline 3 & 3 & 4 & 0.366 & 0.1864 & 120 & 80 \\
\hline 4 & 4 & 5 & 0.3811 & 0.1941 & 60 & 30 \\
\hline 5 & 5 & 6 & 0.819 & 0.707 & 60 & 20 \\
\hline 6 & 6 & 7 & 0.1872 & 0.6188 & 200 & 100 \\
\hline 7 & 7 & 8 & 0.7114 & 0.2351 & 200 & 100 \\
\hline 8 & 8 & 9 & 1.03 & 0.74 & 60 & 20 \\
\hline 9 & 9 & 10 & 1.044 & 0.74 & 60 & 20 \\
\hline 10 & 10 & 11 & 0.1966 & 0.065 & 45 & 30 \\
\hline 11 & 11 & 12 & 0.3744 & 0.1298 & 60 & 35 \\
\hline 12 & 12 & 13 & 1.468 & 1.155 & 60 & 35 \\
\hline 13 & 13 & 14 & 0.5416 & 0.7129 & 120 & 80 \\
\hline 14 & 14 & 15 & 0.591 & 0.526 & 60 & 10 \\
\hline 15 & 15 & 16 & 0.7463 & 0.545 & 60 & 20 \\
\hline 16 & 16 & 17 & 1.289 & 1.721 & 60 & 20 \\
\hline 17 & 17 & 18 & 0.732 & 0.574 & 90 & 40 \\
\hline 18 & 2 & 19 & 0.164 & 0.1565 & 90 & 40 \\
\hline 19 & 19 & 20 & 1.5042 & 1.3554 & 90 & 40 \\
\hline 20 & 20 & 21 & 0.4095 & 0.4784 & 90 & 40 \\
\hline 21 & 21 & 22 & 0.7089 & 0.9373 & 90 & 40 \\
\hline 22 & 3 & 23 & 0.4512 & 0.3083 & 90 & 50 \\
\hline 23 & 23 & 24 & 0.898 & 0.7091 & 420 & 200 \\
\hline 24 & 24 & 25 & 0.896 & 0.7011 & 420 & 200 \\
\hline 25 & 6 & 26 & 0.203 & 0.1034 & 60 & 25 \\
\hline 26 & 26 & 27 & 0.2842 & 0.1447 & 60 & 25 \\
\hline 27 & 27 & 28 & 1.059 & 0.9337 & 60 & 20 \\
\hline 28 & 28 & 29 & 0.8042 & 0.7006 & 120 & 70 \\
\hline 29 & 29 & 30 & 0.5075 & 0.2585 & 200 & 600 \\
\hline 30 & 30 & 31 & 0.9744 & 0.963 & 150 & 70 \\
\hline 31 & 31 & 32 & 0.3105 & 0.3619 & 210 & 100 \\
\hline 32 & 32 & 33 & 0.341 & 0.5302 & 60 & 40 \\
\hline
\end{tabular}

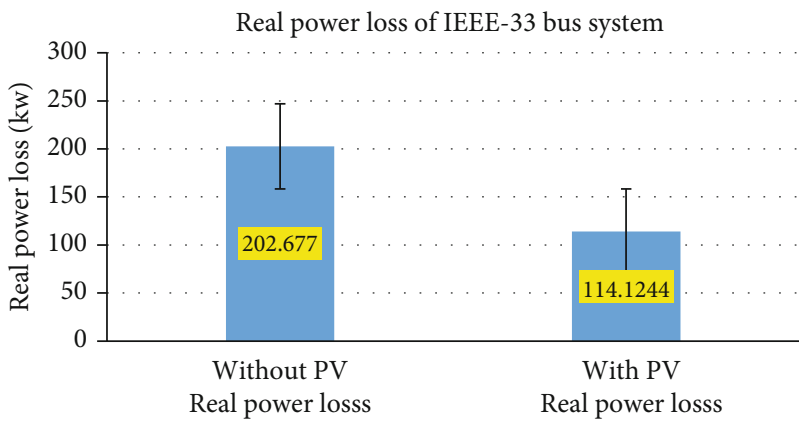

FIgURE 3: Real power loss of the IEEE-33 bus radial feeder.
Step 7. Select the best optimal value that satisfies the constraints if they do not perform mutation to generate new chromosomes.

Step 8. Calculate the fitness value for a new set of generated chromosomes.

Step 9. Increase the count of iteration by 1 and repeat Steps 5 to 8 until the maximum iteration count reaches.

After the completion of the 9 steps, the optimal solution is obtained. The chromosomes obtained at the final step includes the best location and size of the PV generated. Finally, the optimal place selected by GA is again evaluated by GIS. The location of PV generation is decided by the combination of the load flow result and the optimization 


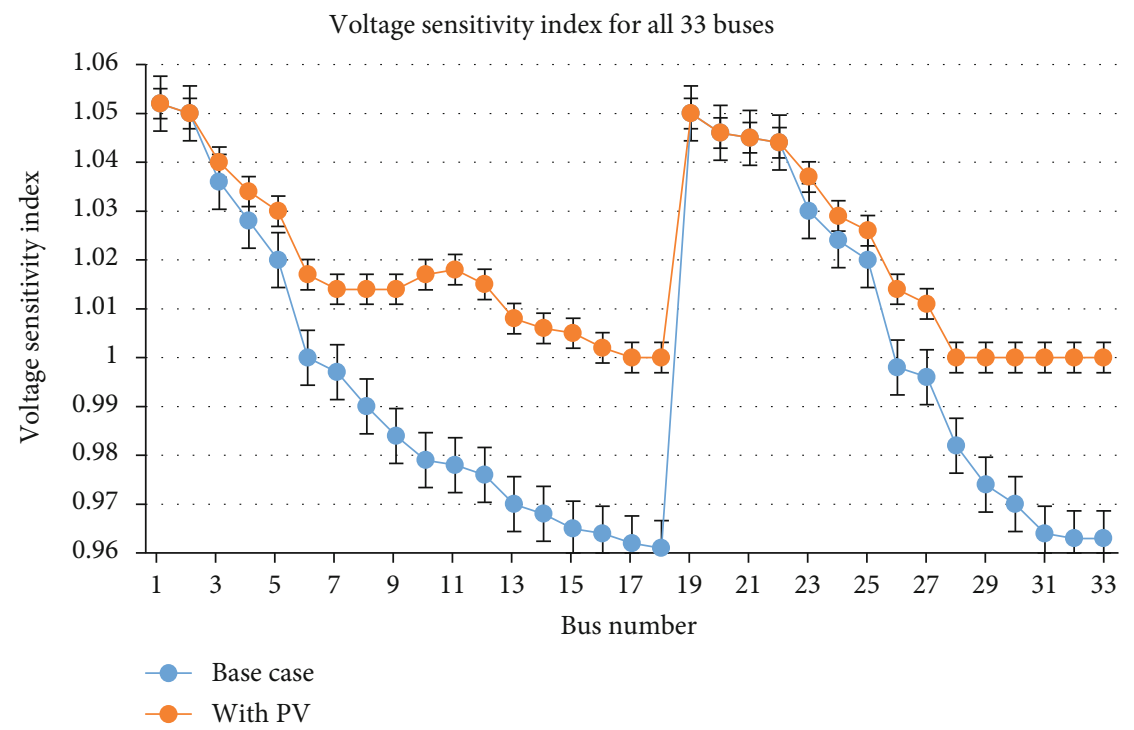

Figure 4: VSI value before and after PV integration.

tool of GA and the geographic information system on the ground of installation.

\section{Economic Impact of Integrating PV Generation}

PV generation integration plays a great role in economic development and reduction of global warming. Analyzing the positive and negative impacts of PV generation integration is a very important point. The economic benefit of renewable energy like solar power is very high, and it is the best alternative source of clean energy. Installation of PV generation saves extra loss of energy. Economically, it is cost effective and requires low maintenance cost. Currently, the installation cost of PV generation decreases rapidly and nearly approaches to the cost of fuel, without the environmental cost benefit. The cost effectiveness of PV generation installation with the existing radial feeders is determined by the minimized power loss. The optimum cost benefit should be conserved and requirements should be fulfilled. The environmentally friendly nature of PV generation has great contribution to economic development and to the mitigation of global warming and environmental pollution.

\section{Result and Discussions}

The IEEE- 33 bus standard test system is used to implement the proposed method. Figure 2 shows the structure of the radial distribution system in this study. The line and load data of the IEEE-33 bus radial feeder are given in Table 2 taken from [20]. The single-line diagram of the IEEE-33 bus radial feeder shown in Figure 2 has a total load of 3.715 MW and 2.3 Mvar. To integrate PV generation with a radial feeder, a multiobjective optimization problem is formulated by considering different constraints to be satisfied.
The real power loss of the radial distribution system is reduced from $202.677 \mathrm{kw}$ to $114.1244 \mathrm{kw}$ due to PV generation integration and saves $43.33 \%$ of the active power loss. The smooth and sustainable power supply is maintained by reducing the power loss and enhancing the voltage profile in radial distribution networks. Using the GA algorithm, PV generation was integrated at bus 29 with $0.975 \mathrm{MW}$ capacity and enabled to reduce the power loss to $114.1244 \mathrm{kw}$ as presented in Figure 3.

The reduction of real power loss increases the voltage profile of weak buses to maintain the minimum threshold voltage at all nodes. The voltage sensitivity index (VSI) result indicates that after PV integration, the voltage profile of the radial feeders satisfies the minimum threshold value. The VSI value was used to determine the most sensitive bus for PV generation integration from the 33 buses. The VSI values before and after PV integration are shown in Figure 4. The reduction of power loss contributes to reliability enhancement, voltage profile improvement, and power quality improvement.

The voltage profile of the IEEE-33 bus system is enhanced to be more than $0.95 \mathrm{pu}$ after PV integration, as shown in Figure 5. This indicates that the reduction of power loss in the distribution system can improve the voltage profile of the node terminals. The minimum voltage of the base case is $0.913 \mathrm{pu}$ whereas the minimum voltage after PV generation installation is $0.95 \mathrm{pu}$. The minimum voltage sensitivity index enables to increase from 0.9611 to 1 after PV generation installation. The distance from the grid has great impact and brings variation in voltage profile. The voltage profile increases from bus 19 rapidly to 20 , and this is due to distance of nodes from the grid.

\section{Conclusion}

The PV generation integration using GA and GIS improves the performance of the radial distribution network. The 


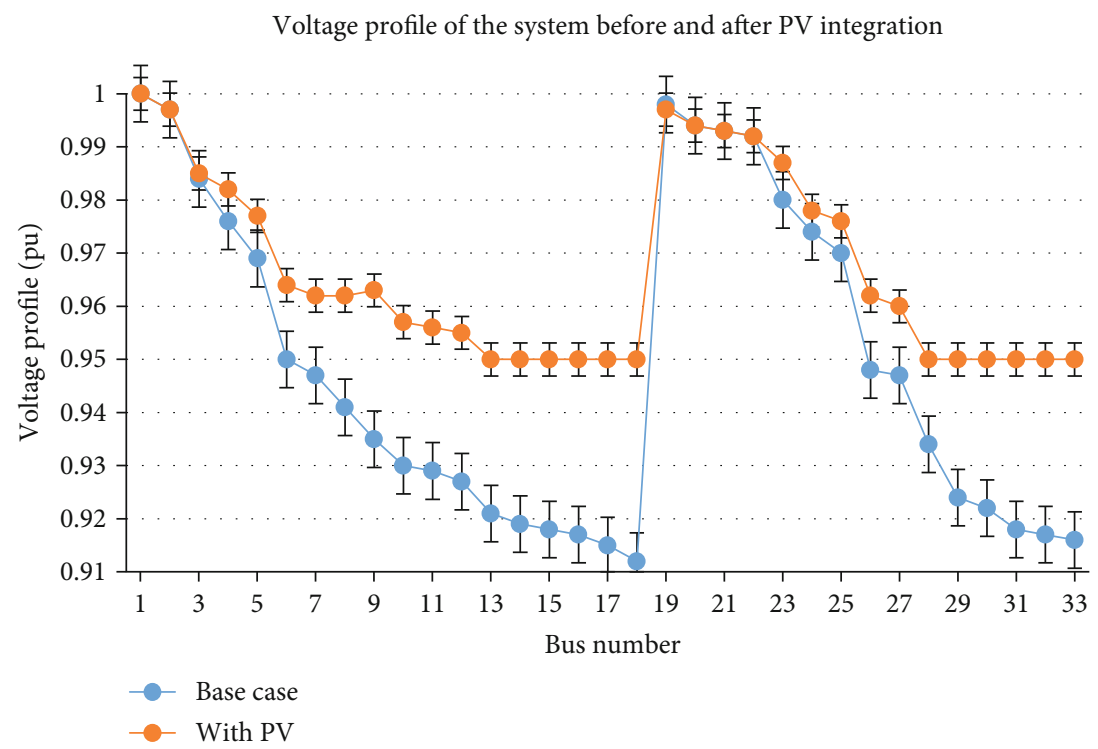

Figure 5: IEEE-33 bus voltage profile before and after PV integration.

power loss of the radial distribution network is reduced due to $\mathrm{PV}$ generation integration while improving the voltage profile of the system. The voltage sensitivity index and GIS are used to identify the optimal place of PV generation integration to the grid. The penetration of PV generation has great impact on network performances like power flow and voltage fluctuation. The reverse power flow and voltage variation are reduced by optimally placing PV generation in radial feeders as different constraints are kept satisfied. Integration of PV generation has significant impact on saving electricity, maintaining the power quality of the network, and balancing the power demand and supplied. The free availability and pollution-free characteristics of PV generation make it more preferable and catches the attention of electrical engineers considering it as an alternative energy source of electricity. The significance of optimally placing and sizing PV generation to reduce power loss is more affected by geographical information, solar irradiance of the specific site, and the availability of space selected as an optimal place by GA and GIS. GIS-based integration of PV generation in radial feeders with GA improves the overall performance of distributed systems in terms of power quality and sustainable delivery of power to end users for rapid electricity demand response.

\section{Data Availability}

All data used during this study are included within this article.

\section{Conflicts of Interest}

The authors declare that there are no conflicts of interest regarding to the publication of this article.

\section{References}

[1] H. Sadeghian, M. H. Athari, and Z. Wang, "Optimized Solar Photovoltaic Generation in a Real Local Distribution Network," in 2017 IEEE Power \& Energy Society Innovative Smart Grid Technologies Conference (ISGT), Washington, DC, USA, 2015.

[2] Y. Tang, S. Member, R. Ayyanar, and S. Member, "Methodology of automated protection analysis for large distribution feeders with high penetration of photovoltaic systems," IEEE Power and Energy Technology Systems Journal, vol. 4, pp. 19, 2016.

[3] A. Guwaeder and R. Ramakumar, "Optimal Integration of PV Generation in Distribution Systems," in 2018 IEEE Conference on Technologies for Sustainability (SusTech), pp. 1-5, Long Beach, CA, USA, 2019.

[4] A. Gagliano, F. Patania, F. Nocera, A. Capizzi, and A. Galesi, "GIS-based decision support for solar photovoltaic planning in urban environment," Sustainability in Energy and Buildings, vol. 22, pp. 865-874, 2013.

[5] Y. Charabi, M. Ben, H. Rhouma, and A. Gastli, "GIS-based estimation of roof-PV capacity \& energy production for the Seeb region in Oman," in 2010 IEEE International Energy Conference, vol. 2, pp. 41-44, Manama, Bahrain, 2010.

[6] P. Jirapong, P. Bunchoo, P. Thararak, A. Supannon, and S. Burana, "Effect of Upgrading Primary Feeders from Radial to Loop Arrangement on Electrical Distribution System Performance," in 2015 12th International Conference on Electrical Engineering/Electronics, Computer, Telecommunications and Information Technology (ECTI-CON), Hua Hin, Thailand, 2015.

[7] “"Ethiopia - Energy export," Ethiopia Energy Trade Development and Promotion," 2018, https://www.export.gov/ article?id=Ethiopia-Energy.

[8] A. Fazliana, A. Kadir, T. Khatib, and W. Elmenreich, "Integrating photovoltaic systems in power system : power quality impacts and optimal planning challenges," International Journal of Photoenergy, vol. 2014, Article ID 321826, 7 pages, 2014. 
[9] T. S. Saggu and L. Singh, "Comparative analysis of custom power devices for power quality improvement in non-linear loads," in 2015 2nd International Conference on Recent Advances in Engineering \& Computational Sciences (RAECS), Chandigarh, India, December, 2016.

[10] P. Anjana, V. Gupta, H. P. Tiwari, and N. Gupta, "PV source integrated micro-grid for power quality improvement," in 2016 IEEE/PES Transmission and Distribution Conference and Exposition (T\&D), Dallas, TX, USA, 2016.

[11] V. R. Pannase and H. B. Nanavala, "A review of PV technology power generation, PV material, performance and its applications," in 2017 International Conference on Inventive Systems and Control (ICISC), pp. 1-5, Coimbatore, India, 2017.

[12] L. V. Teli and H. T. Jadhav, "A review on protection of capacitor in power quality industry," in 2018 International Conference on Current Trends towards Converging Technologies (ICCTCT), pp. 1-5, Coimbatore, India, 2018.

[13] W. J. Praiselin and J. Belwin Edward, "Improvement of power quality with integration of solar PV and battery storage system based micro grid operation," in 2017 Innovations in Power and Advanced Computing Technologies (i-PACT), pp. 1-5, Vellore, India, 2017.

[14] A. Khattak, A. U. Khattak, Z. Ullah, K. Ali, and U. Yousaf, "Analysis and optimization of radial distribution network using GIS and GPS techniques," International Journal of Computer Science and Information Security, vol. 14, no. 11, pp. 1-6, 2016.

[15] M. A. Tolba, V. N. Tulsky, and A. A. Z. Diab, “Optimal sitting and sizing of renewable distributed generations in distribution networks using a hybrid PSOGSA optimization algorithm," in 2017 IEEE International Conference on Environment and Electrical Engineering and 2017 IEEE Industrial and Commercial Power Systems Europe (EEEIC/I\&CPS Europe), pp. 16061612, Milan, Italy, 2017.

[16] V. J. Mohan and T. A. D. Albert, "Optimal sizing and sitting of distributed generation using particle swarm optimization guided genetic algorithm," in Advances in Computational Sciences and Technology, vol. 10, no. 5pp. 709-720, Research India Publications, 2017.

[17] H. A. M. Prasanna, M. V. L. Kumar, and T. Ananthapadmanabha, "Genetic algorithm based optimal allocation of a distributed generator in a radial distribution feeder," in 2014 International Conference on Circuits, Power and Computing Technologies [ICCPCT-2014], vol. 184, 190 pages, Nagercoil, India, 2014.

[18] M. Sedighi, A. Igderi, A. Dankoob, and S. M. Abedi, "Sitting and sizing of DG in distribution network to improve of several parameters by PSO algorithm," in 2010 International Conference on Mechanical and Electrical Technology, pp. 533-538, Singapore, 2010.

[19] M. Abdel-Akher, "Voltage stability analysis of unbalanced distribution systems using backward/forward sweep load-flow analysis method with secant predictor," IET Generation Transmission and Distribution, vol. 7, no. 3, pp. 309-317, 2013.

[20] A. L. Lowell, At War with Academic Traditions in America, vol. 83, no. 6, 1935Harvard University Press, 1935. 